\title{
Determinants of pro-environmental behavior among excessive smartphone usage children and moderate smartphone usage children in Taiwan
}

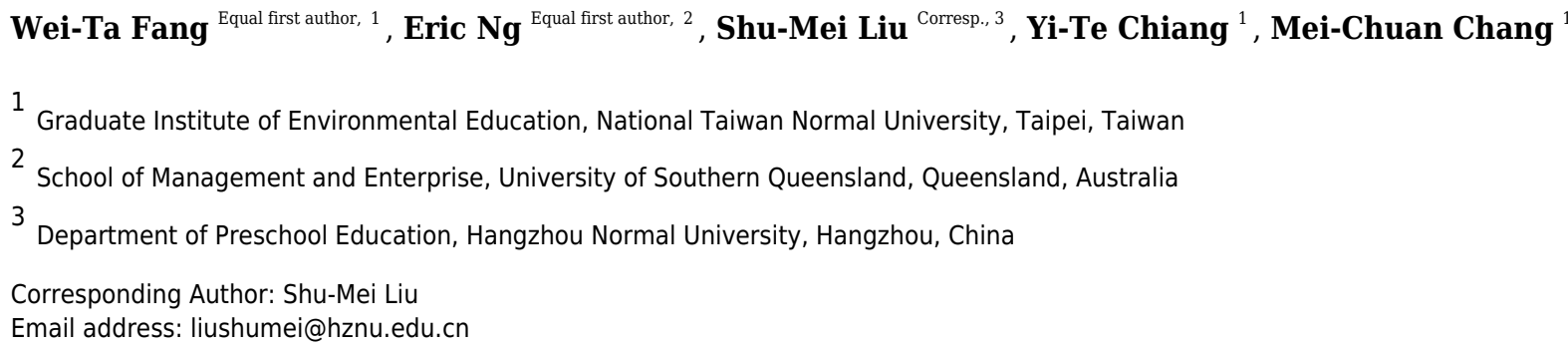

Introduction: Although there is evidence linking the relationships between smartphone usage with health, stress, and academic performance; however, there is still inadequate knowledge about the influence on pro-environmental behaviors. This study seeks to bridge this gap by adapting the theory of attribution framework to examine the effects of personal norms, social norms, perceived behavioral control on pro-environmental behavior of smartphone usage in children. Methods: A total of 225 children aged between 11 to 12 from eight selected public primary schools at the Hsinchu Science and Industrial Park in Taiwan were surveyed. Two distinct groups (excessive versus moderate usage) were purposefully selected for comparison, of which 96 participants were excessive smartphone users while the remaining 129 were moderate smartphone users. Results: Findings revealed significant differences between excessive and moderate smartphone usage children groups in personal norms $(p<0.001)$, social norms $(p=0.002)$, perceived behavioral control $(p=0.001)$, and pro-environmental behavior $(p=0.001)$. Findings for excessive smartphone usage children showed that social norms $(\beta=0.428, t=4.096 * * *, p$ $<0.001$ ) had a direct predictive impact on pro-environmental behavior. In contrast, while there was no direct path established between personal norms and pro-environmental behavior ( $\beta=0.177, t=1.580, p>0.05)$, as well as social norms and pro-environmental behavior for moderate smartphone usage children $(\beta=0.181, t=1.924, p>0.05)$, but such a relationship could be developed through the mediating effect of perceived behavioral control $\left(\beta=0.497, t=4.471^{* * *}, p<0.001\right)$. Discussion: Results suggested that excessive smartphone usage children lack positive perceived behavioral control, and their pro-environmental behavior could only be predicted through explicit social norms. Whereas, pro-environmental behavior of moderate smartphone usage children was implicitly influenced by personal norms through perceived behavioral control. 


\title{
1 Determinants of pro-environmental behavior among
}

2 excessive smartphone usage children and moderate

3 smartphone usage children in Taiwan

4

5

6

7

8

\author{
Wei-Ta Fang ${ }^{1+}$, Eric $\mathrm{Ng}^{2+}$, Shu-Mei Liu ${ }^{3 *}$, Yi-Te Chiang ${ }^{1}$, and Mei-Chuan Chang ${ }^{1}$ \\ ${ }^{1}$ Graduate Institute of Environmental Education, National Taiwan Normal University, Taipei \\ 116, Taiwan \\ ${ }^{2}$ School of Management and Enterprise, University of Southern Queensland, Queensland 4350, \\ Australia \\ ${ }^{3}$ Department of Preschool Education, Hangzhou Normal University, Hangzhou, 311121, China
}

Corresponding Author:

Shumei Liu $^{3}$

2318 Yuhangtan Road, Yuhang District, Hangzhou City, Zhejiang Province, PR China, 311121

Email address: liushumei@hznu.edu.cn; 20190115@hznu.edu.cn

${ }^{+}$Equal first author; these authors contributed equally to this work.

\section{Abstract}

Introduction: Although there is evidence linking the relationships between smartphone usage with health, stress, and academic performance; however, there is still inadequate knowledge about the influence on pro-environmental behaviors. This study seeks to bridge this gap by adapting the theory of attribution framework to examine the effects of personal norms, social norms, perceived behavioral control on pro-environmental behavior of smartphone usage in children.

Methods: A total of 225 children aged between 11 to 12 from eight selected public primary schools at the Hsinchu Science and Industrial Park in Taiwan were surveyed. Two distinct groups (excessive versus moderate usage) were purposefully selected for comparison, of which 96 participants were excessive smartphone users while the remaining 129 were moderate smartphone users.

Results: Findings revealed significant differences between excessive and moderate smartphone usage children groups in personal norms $(p<0.001)$, social norms $(p=0.002)$, perceived behavioral control $(p=0.001)$, and pro-environmental behavior $(p=0.001)$. Findings for excessive smartphone usage children showed that social norms $\left(\beta=0.428, t=4.096^{* * *}, p\right.$ $<0.001)$ had a direct predictive impact on pro-environmental behavior. In contrast, while there was no direct path established between personal norms and pro-environmental behavior $(\beta=$ $0.177, t=1.580, p>0.05)$, as well as social norms and pro-environmental behavior for moderate smartphone usage children $(\beta=0.181, t=1.924, p>0.05)$, but such a relationship could be 
40 developed through the mediating effect of perceived behavioral control $(\beta=0.497, t=4.471 * * *$, $41 p<0.001)$.

42 Discussion: Results suggested that excessive smartphone usage children lack positive perceived 43 behavioral control, and their pro-environmental behavior could only be predicted through 44 explicit social norms. Whereas, pro-environmental behavior of moderate smartphone usage 45 children was implicitly influenced by personal norms through perceived behavioral control.

\section{Introduction}

48 Nowadays, smartphones are becoming increasingly popular that have brought many changes to

49

50

51

52

53

54

55

56

57

58

59

60

61

62

63

64

65

66

67

68

69

70

71

72

73

74

75

76

77

78

79 our day-to-day lives, particularly with the ease of access to a vast variety of mobile applications for the purpose of internet browsing, gaming, social networking, communication, and so on. This phenomenon has seen the number of smartphone users grow steadily from 2.5 billion in 2016 to 2.9 billion in 2018 and is expected to reach 3.8 billion by 2021 globally (Statista, 2020). The growth is stimulated by the many benefits (e.g. entertainment, banking, socializing, and gaming) offer by smartphones, and this has been attested by past studies (Kang \& Jung, 2014; Lemola et al., 2015; Susanto et al., 2016). Although there are numerous advantages of using smartphones, but several side effects have also arisen due to the excessive smartphone usage. Particularly, the widespread use of smartphones is regarded as a factor influencing pro-environmental behavior, leading to disconnect people from the natural environment which has become substantial worldwide psychological and behavioral issues (Kadir et al., 2015; Lee et al., 2014; Chiang et al., 2019). While it remains controversial whether smartphone usage cause disconnectedness between people and natural environment (Fletcher, 2017; Miles et al., 2018), studies have found that adults who spent extended amount of time on smartphone in a day are more likely to exhibit a stronger negative pro-environmental behavior (Kesebir \& Kesebir, 2017; Miles et al., 2018). Such extensive smartphone usage behavior is not only limited to adults, but also evident in children who are increasingly smartphone users nowadays. The smartphone technology has changed a child's growth and development, and there is evidence to support a close correlation between health, behavior, and smartphone usage (Dennison et al., 2013; Lee et al., 2014).

Studies show that children have spent more time and energy on smartphones nowadays that have led to a decrease in their physical outdoor activities and curiosity about the natural environment (Haug et al., 2015; Tian et al., 2018). Other studies have also investigated several different aspects of smartphone usage, such as factors influencing smartphone usage (Aljomaa et al., 2016; Park et al., 2013), impact of smartphone usage on social relationships (Choi et al., 2012), the effects of smartphone usage on academic performance (Samaha \& Hawi, 2016), the relationship between smartphone usage and stress (Chiu, 2014; Wang et al., 2015), and relationship between smartphone usage and social anxiety and loneliness (Gao et al., 2016). However, there are very few studies attempted to combine the two fields of smartphone usage and environmental behaviors together, let alone explore their relationship. Therefore, the key focus of this study is to fill this gap by specifically investigating the impact of smartphone usage on children's pro-environmental behaviors. This is particularly important because experiences 
80

81

82

83

84

85

86

87

88

89

90

91

92

93

94

95

96

97

98

99

100

101

102

103

104

105

106

107

108

109

110

111

112

113

114

115

116

117

118

119

gained through interactions with the environment during the early human development phase can have a considerable influence on a person's perception of the environment (Bandura, 2006).

\section{Conceptual framework and hypotheses}

In the present study, we used Attribution Theory to explain the causes of children's proenvironmental behavior. Pro-environmental behavior refers to the behavior of a person who consciously minimizing his/her negative impact on the environment (Kollmuss \& Agyeman, 2002). Attribution Theory posits that a behavior can be influenced by situations that arise from internal and/or external attributions (Heider, 2013; Kassin \& Fein, 2010). Internal attributions refer to causes of behavior related to some internal characteristic, and two key elements involve are: (1) perceived behavioral control, and (2) personal norms (Onu et al., 2019; Wated \& Sanchez, 2005; Xu et al., 2020). Perceived behavioral control is related to an individual's perceived ease or difficulty of performing personal capabilities to control external challenges (Ajzen, 1985). Whereas personal norms refer to the internal motivation of an individual's perceived moral obligations when taking an action; it is a kind of environmental self-awareness and self-discipline, which is believed to be associated with the generation of pro-environmental behavior (Ajzen \& Driver, 1991; Bertoldo \& Castro, 2016; Esfandiar et al., 2019; Thøgersen, 2006). External attributions are causes of behavior that derive from situations outside a person's control. Social norms are a key component of external attributions that goes beyond attitudes that shape people's behaviors with an attempt to conform to a perceived norm (Weiner, 2001; Yoon \& Lee, 2016). Social norms refer to what people generally believe to be typical behaviors or actions in the group and there are reciprocal expectations of the people within a reference group (Paluck et al., 2010). Such an inter-dependence of expectation and action can often result in a strong resistant to change by people. The relationship and influence of these three key variables (i.e. perceived behavioral control, personal norms, social norms) on pro-environmental behaviors will be further discussed next.

\section{Personal norms, social norms and pro-environmental behaviors}

Studies using the theory of value-belief-norm have found personal norms to be one of the key motivations for individuals to be more autonomous and self-demanding to adopt proenvironmental behaviors (Abrahamse et al., 2009; Stern et al., 1999). In a study by Quinn and Burbach (2008), farmers' pro-environmental behaviors to improve surface water quality are found to be positively influenced by personal norms. Other previous studies have also suggested that pro-environmental behaviors are positively affected by personal norms. For example, personal norms can be used to predict recycling and environmentally friendly consumer behaviors (Ahn et al., 2012; Thøgersen, 2006; Turaga, 2010), influence conservation behaviors (Kaiser et al., 2005), increase riding on public transportation (Thøgersen, 2006), and reduce car usage (Abrahamse et al., 2009). Therefore, to understand the effect of personal norms on proenvironmental behaviors of children using smartphone in Taiwan, the following hypotheses are proposed:

Hypothesis 1 (H1). Personal norms influence the pro-environmental behavior of excessive smartphone usage children. 
Hypothesis 6 (H6). Personal norms influence the pro-environmental behavior of moderate smartphone usage children.

Farrow et al. (2017) have identified various conceptualizations of social norms that are used to investigate the effects of social norms on pro-environmental behavior, and there is evidence to support the relationship. Previous studies have also used different theoretical models of behavior (e.g. Theory of Planned Behavior, Theory of Normative Expectations) from the social psychology and economics literature to explore the influence of social norms on proenvironmental behaviors, and the findings indicate the existence of a relationship between them (Azjen, 1991; Lapinski \& Rimal, 2005). Vu et al. (2020) reveal that peer farmers' behaviors have a positive influence on farmers' adoption of organic fertilizer, and socially desired behaviors have been used more broadly to encourage pro-environmental farming practices in developed countries. Findings from a study by Duron-Ramos et al. (2020) suggest that children who show more altruistic values and sociable behavior toward others are more likely to demonstrate proenvironmental behaviors. Other studies have also found social norms affect recycling, organic food purchases, and the utilization of public transportation behaviors (Ferdinando et al., 2011; Thøgersen, 2006). Thus, this study seeks to understand the role that social norms play in the proenvironmental behaviors of children using smartphone in Taiwan. Given the above, two hypotheses are proposed:

Hypothesis 2 (H2). Social norms influence the pro-environmental behavior of excessive smartphone usage children.

Hypothesis 7 (H7). Social norms influence the pro-environmental behavior of moderate smartphone usage children.

\section{Personal norms, social norms and perceived behavioral control}

Perceived behavioral control can be divided into internal and external controls. Internal control factors relate to personal behaviors such as personal skills, capabilities, or emotions, while external control factors include information, opportunities, and dependence on others from the outside world (Chan \& Bishop, 2013). Thus, perceived behavioral control is likely to be affected by both internal (i.e. personal norms) and external (i.e. social norms) attributions.

Previous studies related to reduce car usage (Abrahamse et al., 2009), adoption of organic fertilizer (Vu et al. 2020), energy saving intention (Ru et al., 2018), sustainable food consumption (Han \& Hansen, 2012), and binning behavior in national parks (Esfandiar et al., 2019) have shown that personal norms affect perceived behavioral control. A study by Wall et al. (2008) on commuter travel-mode choices indicate that personal norms and perceived behavioral control are invoked together and can have significant influence on car usage intention. Although personal norms may be present, but a low level of perceived behavioral control can still prevent that norm from being converted into pro-environmental behaviors. Thus, it is proposed that the following hypotheses are examined in relation to the pro-environmental behaviors of children using smartphone in Taiwan.

Hypothesis 3 (H3). Personal norms influence the perceived behavioral control of excessive smartphone usage children. 
Hypothesis 8 (H8). Personal norms influence the perceived behavioral control of moderate smartphone usage children.

Prior studies have also revealed that social norms are related to perceived behavioral control (Bamberg \& Möser, 2007). In the context of recycling and organic food purchase behaviors, Ferdinando et al. (2011) suggest that social norms have positive influence on perceived behavioral control. Another study by Leung and Rosenthal (2019) also found that there is a link between social norms and perceived behavioral control toward recycling intention and behaviors. When fellow colleagues are supportive of a particular behavior, individuals tend to perceive a stronger norm and have more behavioral control that contribute to positive recycling behaviors. Other areas of studies that suggested a relationship between social norms and perceived behavioral controls include: waste separation (Zhang et al., 2015), adolescents' environmental intention (Lee, 2011), green poultry by farmers (Gholamrezai et al., 2021), tourists' responsible environmental behaviors (Wang et al., 2018). As such, the following hypotheses are proposed to explore the pro-environmental behaviors of children using smartphone in Taiwan.

Hypothesis 4 (H4). Social norms influence the perceived behavioral control of excessive smartphone usage children.

Hypothesis 9 (H9). Social norms influence the perceived behavioral control of moderate smartphone usage children.

\section{Perceived behavioral control and pro-environmental behavior}

According to Ajzen (1991), perceived behavioral control is a crucial factor in the Theory of Planned Behaviors that affects behaviors. Past studies in the fields of conservation behavior intention (Kaiser et al., 2005), household-waste prevention behaviors (Bortoleto et al., 2012), air pollution prevention behaviors (Liu et al., 2018), recycling behaviors (Leung \& Rosenthal, 2019), and eco-friendly behaviors of travelers (Han, 2015) have shown that perceived behavioral control plays a role in influencing pro-environmental behaviors. Given that perceived behavioral control may be influenced by both personal and social norms, it is posit that perceived behavioral control can possibly be a moderator between personal norms, social norms, and proenvironmental behaviors. Thus, the following hypotheses are proposed for the pro-environmental behaviors of children using smartphone in Taiwan.

Hypothesis 5 (H5). Perceived behavioral control influences the pro-environmental behavior of excessive smartphone usage children.

\section{Hypothesis 10 (H10). Perceived behavioral control influences the pro-environmental} behavior of moderate smartphone usage children.

This study aims to investigate the pro-environmental behavior of children in Taiwan, whereby the ownership of smartphones in children aged between 10 to 12 has grown significantly from $38.7 \%$ in 2013 to $82.7 \%$ in 2019 (The Child Welfare League Foundation, 2019b). This alarming trend has elicited considerable related discussions (e.g. counter measurements for smartphone usage, responsibilities of the government and parents, social impact, cyber bullying), and is an increasingly concerning social phenomenon in Taiwan that requires further understanding of the situation (The Child Welfare League Foundation, 2019a). This research seeks to examine how 
200

201

202

203

204

205

206

207

208

209

210

211

212

213

214

215

216

217

218

219

220

221

222

223

224

225

226

227

228

229

230

231

232

233

234

235

236

237

238

239

internal (i.e. perceived behavioral control, personal norms) and external (i.e. social norms) attributions are related to children's pro-environmental behavior. Thus, this study proposed the following research framework (Figure 1) to be investigated.

\section{Inserted Fig 1 here}

\section{Materials \& Methods}

\section{Research area}

This study was carried out in Hsinchu City, Taiwan, one of the major technological and industrial cities in Asia as described in Fang et al. (2017). Specifically, the research was undertaken at the elementary schools around the Hsinchu Science Park, which was founded in 1980 with a development area of 653 hectares at the Hsinchu Park that resembles the Silicon Valley in the United States (Hsinchu Science Park, 2016). In 2017, there were 520 companies in Hsinchu Science Park with a total of 150,000 employees that generated an overall revenue exceeding NT\$1 trillion (Hsinchu Science Park, 2016). There were several elementary schools situated in the Hsinchu Science Park area that cater to the needs of many families working there.

\section{Participants and procedure}

A probability cluster sampling method was adopted in this study with the selection of eight public elementary schools around the Hsinchu Science and Industrial Park located at Hsinchu City, Taiwan as described in Fang et al. (2017). A total of 16 classes (one each from grades five and six, age between 11 to 12) were randomly selected from eight elementary schools. Prior to conducting this research study, written information (e.g. purpose and objectives of the study, no financial incentives or payments involve) about the survey and consent forms were sent to children, parents, school principals and class teachers to brief them about the research and obtain their agreement to participate in the study as outlined in Fang et al. (2017). At the same time, their rights to withdraw from the study at any time were also conveyed to them. Participants were again informed verbally about the purpose of the study and procedures to follow, as well as given the opportunity to have their queries answered prior to completing the survey. Participants had approximately 15 minutes in class to complete the questionnaire survey and the class teacher would collate them when completed as described in Fang et al (2017). All participants, parents, class teachers and school principals provided written informed consent. The National Taiwan Normal University Research Ethics Committee had approved (201707HS001) this study and endorsed informed consent acquired from the respective class teachers and school principals as adequate. In addition, parents could opt their child out of the study at any time prior to the questionnaire commencing. A total of 260 questionnaires were distributed and were all returned. However, 35 were considered invalid due to their incomplete responses. Therefore, statistical analysis was performed using the remaining 225 questionnaires.

\section{Measures}

This study was supported by the literature reviewed on the impact of cognitive and psychological factors on pro-environmental behavior (De Leeuw \& Valois, 2014; De Leeuw et al., 2015; Esfandiar et al., 2019). Data were collected as previously described in Fang et al. (2017). As described in Fang et al. (2017), this study specifically sought to measure three key dimensions: 
240 (1) perceived behavioral control, (2) personal norms, and (3) social norms that were considered

241 influential to pro-environmental behavior (Culiberg \& Elgaaied-Gambier, 2016; Esfandiar et al., 242 2019; Farrow et al., 2017). This research adopted the self-administered questionnaire survey

243 method that included two key sections related to background and psychological variables (please 244 see Appendix A1).

\section{Background variables}

246 In the background variables, personal data were gathered about participants' gender, grade level, 247 and smartphone usage. Gender and grade level were measured through nominal variables (i.e.

248 Gender - Male or Female; Grade level - Grade 5 or Grade 6), whereas smartphone usage was 249 measured by the question "How many hours per day do you usually spend on smartphone during 250 a typical day?" with five possible multiple-choice responses (i.e. none, less than 1 hour, between 2511 to 2 hours, between 2 to 3 hours, between 3 to 4 hours, between 4 to 5 hours, more than 5 252 hours). While there is no one single agreed definition for excessive smartphone usage, but it can 253 be broadly defined as the extended use of smartphone by individuals that interferes their daily 254 lives (Hair Jr et al., 2016). Studies have shown that there were about 50\% of children used 255 smartphones for more than 2 hours per day (Haug et al., 2015), and approximately $70 \%$ of 256 children's daily screen time exceeded the American Academy of Pediatrics recommendations 257 (i.e. more than two hours per day) (Hair Jr et al., 2014; Henseler, 2017). Thus, for the purpose of 258 this study, excessive smartphone usage is considered to be more than two hours per day. In this 259 research study, two groups of children (i.e. excessive smartphone usage group - more than two 260 hours per day of smartphone usage, and moderate smartphone usage group - less than 2 hours of 261 smartphone usage per day) were purposefully selected for comparison.

\section{Psychological variables}

263 The psychological variables in the questionnaire survey were mainly compiled and adapted from 264 previously conducted pro-environmental behavior research studies, specifically related to 265 perceived behavioral control, social norms and personal norms dimensions (Abrahamse et al., 266 2009; Henseler, 2017; Thøgersen, 2006). As for the questionnaire items for pro-environmental 267 behavior, they were predominantly derived from the classification by Erdogan and Ok (2011). 268 Three experts and 50 children in grades five and six had pre-tested the questionnaire survey and 269 some changes (e.g. simplified wordings) had been made accordingly to ensure an easier 270 understanding of the context. Nonetheless, the original meaning of the items adapted from the 271 previous studies were retained. A five-point Likert scale (i.e., 1 = "Strongly disagree" to 5 = 272 "Strongly agree") was applied for the measurement of the personal norms, social norms, 273 perceived behavioral control, and pro-environmental behaviors in this study as described in Fang 274 et al. (2017). The Cronbach's $\alpha$ values of the respective dimensions were perceived behavioral 275 control (0.686), personal norm (0.766), social norm (0.886), and pro-environmental behavior 276 (0.846), which demonstrated internal reliability since their values were greater than the 0.6 277 requirement. The Kaiser-Meyer-Olkin and Spherical Bartlett tests as described in Fang et al. 278 (2018) had indicated a value of 0.885 and $2496.758(\mathrm{p}<0.001)$ respectively. Factor analyses 279 were subsequently conducted in PLS and the factor loading of each question in the key 
280

281

282

283

284

285

286

287

288

289

290

291

292

293

294

295

296

297

298

299

300

301

302

303

304

305

306

307

308

309

310

311

312

313

314

315

316

317

318

dimensions had exceeded the value of 0.4 (Pett et al., 2003). Given the outcome of these test values, the scales used for the psychological variables could be regarded as reliable.

\section{Statistical analysis}

The statistical analysis in this study was carried out as previously described in Fang et al. (2017) and Fang et al. (2018), using the Statistical Package for Social Sciences (version 22) software program. Specifically, frequency analysis was used to identify the total number of occurrences, the mean and standard deviation (SD) scores for the demographic questions and items in the key dimensions of perceived behavioral control, personal norms, social norms, and proenvironmental behavior. In addition, Pearson's correlation coefficient was used to evaluate the intensity and direction of the relationship between the key dimensions. Whereas the multiple regression analysis was used to determine the influence of perceived behavioral control, personal norms, social norms on pro-environmental behavior. The SmartPLS 2.0 statistical software was utilize in this study to perform the path analysis, which were then used to assess the magnitude and significance of the causal relationships between perceived behavioral control, personal norms, social norms, and pro-environmental behavior.

\section{Results}

\section{Descriptive statistics}

Overall results showed that both males $(48.9 \%, \mathrm{n}=110)$ and females $(51.1 \%, \mathrm{n}=115)$ were relatively well represented in this study. Among them, $47.6 \%(n=107)$ were in grade five and the remaining $52.4 \%(\mathrm{n}=118)$ were in grade six. Of the two control groups investigated, the excessive smartphone usage group accounted for $42.7 \%(n=96)$, whereas the moderate smartphone usage group was $57.3 \%(n=129)$. Findings revealed significant differences between males and females in their perceived behavioral control $(\mathrm{df}=223$, two-tailed, $t=2.126>1.96, p$ $=0.035$ ). Similarly, significant differences were also identified between grade five and grade six children in terms of their personal norms $(\mathrm{df}=223$, two-tailed, $t=2.095>1.96, p=0.037)$ and perceived behavioral control $(\mathrm{df}=223$, two-tailed, $t=2.498>1.96, p=0.013)$. Furthermore, significant differences between excessive smartphone usage group children and moderate smartphone usage group children were also evident in personal norms ( $\mathrm{df}=223$, two-tailed, $t=$ $4.693>1.96, p<0.001)$, social norms $(\mathrm{df}=223$, two-tailed, $t=3.205>1.96, p=0.002)$, perceived behavioral control ( $\mathrm{df}=223$, two tailed, $t=3.465>1.96, p=0.001)$, and proenvironmental behavior ( $\mathrm{df}=223$, two-tailed, $t=3.520>1.96, p=0.001)$. Table 1 presents a brief summary of the demographic findings and their association with personal norms, social norms, perceived behavioral control, and pro-environmental behavior.

\section{Inserted Table 1 here}

As shown in Table 2, the mean score for the overall perceived behavioral control was 3.62. Among the four perceived behavioral control related items, "I can save water resources" had the highest mean score (3.92), and this was followed by "I can observe environmental cleanliness" (3.80), "I take the initiative to go outdoors" (3.38), and "I have involvement in and disseminate information beneficial to the environment" (3.37). The results indicated an internal consistency 
319 reliability measurement with the Cronbach's $\alpha$ value of 0.686 for perceived behavioral control 320 related items.

321

322

323

324

325

326

327

328

329

330

331

332

333

334

335

336

337

338

339

340

341

342

343

344

345

346

347

348

349

350

351

352

353

354

355

356

357

358

\section{Inserted Table 2 here}

Findings for the overall personal norms revealed a mean score of 3.68. There were three personal norms related items, namely "For self-discipline, I carry my own water cup when I go out" (3.79), "For self-discipline, I carry my own cutlery when I go out" (3.70), and "I must not arbitrarily abandon pets or plant garden plants in the wild" (3.45). Results of the personal norms related items are displayed in Table 3 below. There was a consistent reliable measurement for the personal norms related items with the Cronbach's $\alpha$ value of 0.766 .

\section{Inserted Table 3 here}

Results (see Table 4) indicated that the mean score for the overall social norms was 3.61. There were six social norms related items whereby "People I know do not litter arbitrarily", and "People I know go outdoors instead of staying indoors with air conditioning" had the highest (3.78) and lowest (3.22) mean score respectively. Other items also include: "People I know are aware of how to save water" (3.77), "People I know expect me to go outdoors and use less air conditioning" (3.68), "People I know want me to carry a water cup and cutlery when I go out" (3.63), and "People I know carry their own cutlery when they go out" (3.59). The Cronbach's $\alpha$ value of 0.886 suggested internal consistency for the social norms related items.

\section{Inserted Table 4 here}

In terms of the overall pro-environmental behavior, findings revealed a mean score of 3.32. There were five items related to pro-environmental behavior, and of which "I go outdoors in my free time, rather than watching TV and sitting in front of the computer" received the highest mean score (3.62). This was followed by "I participate in conducting surveys on animal and plant-related activities in the vicinity of the community" (3.52), "I persuade others to sort waste" (3.34), "I visit the park and volunteer" (3.14), and "I participate in environmental activities conducted outdoors" (2.97). Results of the pro-environmental behavior related items are outlined in Table 5 below. The internal consistency reliability for the pro-environmental behaviors related items was measured, with the Cronbach's $\alpha$ value of 0.846 .

\section{Correlation analysis}

As shown in Table 6, the correlation analysis results indicated that personal norms and perceived behavioral control were highly correlated with a value of $0.723(p<0.01)$. The correlation coefficient of the remaining relationships indicated a moderate correlation; social norms and perceived behavioral control $(r=0.520, p<0.01)$; perceived behavioral control and proenvironmental behavior ( $r=0.598, p<0.01)$; personal norms and pro-environmental behavior $(r$ $=0.536, p<0.01)$; social norms and pro-environmental behavior $(r=0.522, p<0.01)$. Hence, personal norms, social norms, perceived behavioral control, and pro-environmental behavior were considered to be correlated.

\section{Inserted Table 6 here}

\section{Regression and path analysis}

Peer) reviewing PDF | (2020:10:54057:2:0:NEW 21 May 2021) 
359 Results of the partial least squares regression analysis indicated different paths influencing pro-

360

361

362

363

364

365

366

367

368

369

370

371

372

373

374

375

376

377

378

379

380

381

382

383

384

385

386

387

388

389

390

391

392

393

394

395

396

397

398

environmental behavior for both excessive smartphone usage, and moderate smartphone usage children. In the excessive smartphone usage group (as shown in Table 7), the average variance extracted (AVE) values for personal norms (0.5297), social norms (0.5363), perceived behavioral control (0.5219), and pro-environmental behaviors ( 0.5782$)$ were above 0.50 . The composite reliability $(\mathrm{CR})$ values for personal norms $(0.7660)$, social norms $(0.8736)$, perceived behavioral control (0.8130), and pro-environmental behaviors (0.8711) were at least 0.70 . Therefore, the model statistically supported the convergent validity and reliability for the measurement model between the latent variables and their respective dimensions (Hair Jr et al., 2016; Hair Jr et al., 2014; Henseler, 2017). The Cronbach's $\alpha$ values for social norms (0.8280), and pro-environmental behaviors $(0.8173)$ were above 0.7 , and thus achieved a high level of internal consistency. While the Cronbach's $\alpha$ values for personal norms $(0.5604)$, and perceived behavioral control (0.6976) were below the value of 0.7 , but they were higher than the acceptable value of 0.5 , which indicated that the survey items had demonstrated an acceptable level of internal consistency. The explanatory power $\left(\mathrm{R}^{2}\right)$ of the affected dimensions were perceived behavioral control (0.2865), and pro-environmental behavior (0.2964).

\section{Inserted Table 7 here}

Figure 2 displayed the path analysis about the relationship between personal norms, social norms, perceived behavioral control, and pro-environmental behavior of excessive smartphone usage children. The bootstrapping method was used to obtain the $t$ value of the path in order to examine the significant level. According to the path analysis for excessive smartphone usage children, personal norms $(\beta=-0.044, t=0.395, p>0.05$ ) had no direct influence on proenvironmental behavior, whereas social norms $\left(\beta=0.428, t=4.096^{* * *}, p<0.001\right)$ had a direct predictive impact. Therefore, $\mathrm{H} 1$ was not supported as there was no evidence of a direct influence of personal norms on pro-environmental behavior for excessive smartphone usage children. However, $\mathrm{H} 2$ was supported since social norms had shown a direct positive influence on pro-environmental behavior for excessive smartphone usage children. Although personal norms $\left(\beta=0.304, t=2.721^{* *}, p<0.01\right)$, and social norms $\left(\beta=0.333, t=2.779^{* *}, p<0.01\right)$ had a significant impact on perceived behavioral control, but there was no evidence suggesting a relationship existed between perceived behavioral control $(\beta=0.220, t=1.823, p>0.05)$ and pro-environmental behavior. Hence, $\mathrm{H} 3$ and $\mathrm{H} 4$ were supported since both personal norms and social norms had a positive influence on perceived behavioral control for excessive smartphone usage children. Conversely, H5 was not supported because perceived behavioral control had no direct effect on pro-environmental behavior for excessive smartphone usage children.

\section{Inserted Fig 2 here}

For the moderate smartphone usage children group (as shown in Table 8), the average variance extracted (AVE) values for personal norms (0.6549), social norms (0.6270), perceived behavioral control (0.6240), and pro-environmental behaviors (0.6441) had exceeded 0.50 . The composite reliability (CR) values for personal norms (0.8496), social norms $(0.9093)$, perceived behavioral control (0.8688), and pro-environmental behaviors (0.9004) were above 0.70 . Thus,

Peer) reviewing PDF | (2020:10:54057:2:0:NEW 21 May 2021) 
399

400

401

402

403

404

405

406

407

408

409

410

411

412

413

414

415

416

417

418

419

420

421

422

423

424

425

426

427

428

429

430

431

432

433

434

435

436

437

the model statistically supported the convergent validity and reliability for the measurement model between the latent variables and their respective dimensions (Hair Jr et al., 2016; Hair Jr et al., 2014; Henseler, 2017). The Cronbach's $\alpha$ values for personal norms (0.7309), social norms (0.8794), perceived behavioral control (0.7989), and pro-environmental behaviors $(0.8618)$ were greater than 0.7 , and therefore indicated a high level of internal consistency. The explanatory power (R2) on the affected dimensions of perceived behavioral control, and pro-environmental behavior were recorded as 0.5697 and 0.5684 respectively.

\section{Inserted Table 8 here}

The path analysis (as shown in Figure 3) displayed the relationship between personal norms, social norms, perceived behavioral control, and pro-environmental behavior of moderate smartphone usage children. In order to determine the level of significance, the bootstrapping method was used to obtain the $t$ value of the path. Analysis results revealed that personal norms and social norms did not have a direct path relationship to pro-environmental behavior, but instead displayed an influence on perceived behavioral control. Therefore, H6 and H7 were not supported since there was no evidence of personal norms and social norms having direct influence on pro-environmental behavior for moderate smartphone usage children. Accordingly, personal norms had a greater impact on perceived behavioral control $\left(\beta=0.664, t=10.357^{* * *}, p\right.$ $<0.001)$ than social norms $\left(\beta=0.153, t=2.160^{*}, p<0.05\right)$, thus H8 and H9 were supported which confirmed the influence of personal norms and social norms on perceived behavioral control for moderate smartphone usage children. Although there was no direct path established between personal norms and pro-environmental behavior, and social norms and proenvironmental behavior, but such a relationship could be developed through the mediating effect of perceived behavioral control $\left(\beta=0.497, t=4.471^{* * *}, p<0.001\right)$. The $P$-values of the paths from personal norms to pro-environmental behavior, and social norms to pro-environmental behavior were greater than the significance levels $(\alpha=0.05)$. Therefore, H10 was supported, whereby perceived behavioral control had a positive influence on pro-environmental behavior for moderate smartphone usage children.

\section{Inserted Fig 3 here}

\section{Discussion}

This study adopted the Social Attribution Theory to explore the impact of personal norms, social norms, and perceived behavioral control on pro-environmental behaviors by two groups of children in Taiwan based on their daily smartphone usage (i.e. excessive versus moderate). The extant literature suggested that there were inadequate studies conducted to understand the relationship between smartphone usage and environmental behaviors, which this study sought to fill the gap by investigating personal norms, social norms, and perceived behavioral control to determine their specific path and level of influence on pro-environmental behaviors. The overall results indicated that moderate smartphone usage children had shown a greater level of proenvironmental behaviors than those children who were excessive smartphone users, and this finding was supported by previous studies (Kesebir \& Kesebir, 2017; Richardson et al., 2018). 
438 The results also revealed support and accepted six (i.e. H2, H3, H4, H8, H9 and H10) of the 10

439 hypotheses, indicating significant direct positive relationship.

440 Excessive smartphone usage children group

441 Results suggested that the relationship between personal norms and pro-environmental

442 behaviors for excessive smartphone usage children was considered weak, and as such $\mathrm{Hl}$ was

443 rejected. This outcome indicated that personal beliefs of the excessive smartphone usage children

444 had minimal influence on their pro-environmental behaviors. The absence of this relationship

445 could be explained through a possible lack of one's desire to conform to pro-environmental

446 behaviors and/or a lack of environmental self-awareness and self-discipline that could contribute

447 to exhibiting pro-environmental behaviors.

448 Findings revealed the support for $\mathrm{H} 2$ since social norm was a major predictive variable of pro-

449 environmental behaviors for excessive smartphone usage children. This implied that excessive

450 smartphone usage children were more likely to display and engage in pro-environmental

451 behavior when they felt under pressure to conform to the expectation and requirement of

452 normative social influence. This could be explained by the cultural context whereby

453 Confucianism, which is an East Asian ethical and philosophical system that emphasizes on social

454 values, has strong culture roots in countries such as China, Korea, Japan, and Singapore (Chang

455 \& Chu, 2007; Westwood \& Chan, 1995). This strong emphasis on social values formed the basis

456 for a sense of belonging to the group, which could explain the results emphasizing a greater

457 influence of social norms for excessive smartphone usage children on their pro-environmental

458 behavior. Hence, pro-environmental behaviors were only predicted through social norms,

459 whereby excessive smartphone usage children followed the rules that regulate their life from

460 explicit standards for proper behaviors.

461 Analysis results also indicated that while both personal norms and social norms had a

462 significant impact on perceived behavioral control (i.e. H3 and H4) on the excessive smartphone

463 usage children, but a relationship between perceived behavioral control and pro-environmental

464 behaviors was not established (i.e. H5). The rejection of this hypothesis (H5) could be due to a

465 lack of individual's beliefs about their personal capabilities to overcome challenges that impeded

466 their exhibition of pro-environmental behaviors. Therefore, pro-environmental behaviors were

467 only predicted through social norms, whereby excessive smartphone usage children followed the 468 rules that regulate their life from explicit standards for proper behaviors.

469

470

471

472

473

474

475

\section{Moderate smartphone usage children group}

For the moderate smartphone usage children group, findings rejected $\mathrm{H} 6$ and $\mathrm{H} 7$ since there was no evidence supporting the direct influence of personal norms on pro-environmental behaviors, and social norms on pro-environmental behaviors. This suggested that the pro-environmental behaviors of the moderate smartphone usage children would neither directly affected solely by their perceived moral obligations toward environment, nor when pressured to conform because

476 of external social influences. 
477 On the other hand, there was evidence in the moderate smartphone usage children group that 478 indicated a direct influence from personal norms to perceived behavioral control, and social 479 norms to perceived behavioral control, hence H8 and H9 were supported. Although personal 480 norms would have provided moderate smartphone usage children the perceived moral 481 obligations to undertake pro-environmental behaviors, but it did not appear to have a direct 482 impact, instead an indirect influence on pro-environmental behaviors was only achieved through

483

484

485

486

487

488

489

490

491

492

493

494

495

496

497

498

499

500

501

502

503

504

505

506

507

508

509

510

511

512

513

514

515

\section{perceived behavioral control. An explanation to this could be that the perceived moral} obligations to the environment itself was not strong enough for moderate smartphone usage children to undertake pro-environmental behaviors, but through self-resilience from perceived behavioral control, pro-environmental behaviors were attained (Ali et al., 2010; Schwarzer \& Warner, 2013). Studies (e.g. Song \& Li, 2019; Tchetchik et al., 2021) showed that individuals with self-resilience attitudes were more likely to demonstrate and adapt positive behavioral change to their surroundings, perception of green living environments and more responsible toward environmental issues. Therefore, personal norms could only affect pro-environmental behaviors through the mediating variable of perceived behavioral control (Abrahamse et al., 2009; Esfandiar et al., 2019). Findings also suggested that perceived behavioral control was a major predictive variable affecting pro-environmental behaviors (i.e. H10) for moderate smartphone usage children. This result aligned with other studies (e.g. De Leeuw et al., 2015) that found perceived behavioral control having a significant role to play in determining proenvironmental behaviors.

\section{Differences between two groups}

There were two key differences in the findings between excessive and moderate smartphone usage children investigated in this study. Firstly, results indicated that social norms were considered a key influencing factor for excessive smartphone usage children's pro-environmental behavior. Social norm had a very strong direct positive association with behavioral intention for excessive smartphone users (Lee et al., 2018), and behavioral intention was the most direct predictor of behavior (Glanz et al., 2015). Thus, social requirements and social expectation were more likely to predict pro-environmental behaviors of excessive smartphone usage children than moderate smartphone usage children. This suggested that excessive smartphone usage children might rely on the role of socializing agents in the development of self-regulation, such as parents (i.e., low levels of parental restrictive mediation), teachers, and peers (Chang et al., 2019), and therefore were unable to develop their own thoughts, feelings, and actions toward the exhibition of pro-environmental behavior (Zimmerman, 2000). As such, their norms could not be internalized due to a lack of self-regulation, resulting in their "following the instructions of the teachers and other adults or acting based on observed actions of the peers" behavior. Therefore, their demonstrated pro-environmental behavior was likely to be coercive and conditional under physical and emotional duress that were not necessarily the intended actual behavior of their own. This supported previous studies (Gökçearslan et al., 2016; Jeong et al., 2016) conducted about predictors of self-regulation on smartphone usage.

Peer) reviewing PDF | (2020:10:54057:2:0:NEW 21 May 2021) 
516 Secondly, the research results revealed that personal norms of moderate smartphone usage 517 children had a greater predictive power on their perceived behavioral control, which

518 subsequently affected pro-environmental behaviors. This indicated that moderate smartphone 519 usage children had internalized their personal norms, and with the perceived ease of their 520 capabilities, to perform pro-environmental behaviors. Hence, the personal norms of the moderate 521 smartphone usage children could have an indirect positive impact on their pro-environmental 522 behaviors via perceived behavioral control. The findings align with previous studies (e.g. Turaga 523 et al., 2010; Thøgersen, 2006; Abrahamse et al., 2009) conducted on the effects of personal 524 norms on environmental behaviors.

\section{Implications, limitations and future research}

526 There are two key implications from the findings in this study. Firstly, pro-environmental

527

528

529

530

531

532

533

534

535

536

537

538

539

540

541

542

543

544

545

546

547

548

549

550

551

552

553

554 behavior of excessive smartphone usage children was predominantly affected by social norms only. Therefore, it is recommended that environmental education programs (formal and informal) at schools need to be targeting independent of knowledge so that children can better understand the relationship between their behavior and the environment. This helps toward attaining a more sustainable pro-environmental behavior of becoming a socially responsible citizen and not just conforming because of the social norm pressure. Next, the increasing concern of excessive smartphone usage by children has also prompted the need to explore different ways to minimize such a harmful behavior. Through the promotion of more outdoor activities and utilizing outdoor venues such as parks and playgrounds, children are then provided with more choices other than engaging with their smartphones (e.g. gaming, internet surfing), therefore reducing the potential of smartphone overuse.

There are several limitations in this research study. First, the primary schools were selected in the proximity of the Hsinchu Science and Industrial Park location and thus the findings are not applicable to other geographical areas. To generalize the findings, further research needs to be conducted with a larger sample and tested accordingly. Secondly, research can also be investigated in other country contexts in the future to provide cross-country comparisons. Lastly, follow-up studies can be conducted to gain further in-depth understanding about the relationship of smartphone usage, and other psychological variables (such as attitudes, beliefs) toward environmental knowledge and behaviors.

\section{Conclusions}

This study has used the Attribution Theory as the basis to examine the causes of children's proenvironmental behavior in Taiwan. Research results revealed that social norms were the key factor affecting the pro-environmental behavior of excessive smartphone usage children. Conversely, personal norms, through the indirect path of perceived behavioral control, had the greatest level of influence on moderate smartphone usage children's pro-environmental behavior. The findings clearly distinguished the pro-environmental behavior path modes between the excessive smartphone usage children and moderate smartphone usage children. Excessive smartphone usage children would only exhibit pro-environmental behavior through social norms, 
555 whereas moderate smartphone usage children displayed higher personal norms and perceived

556

557

558

559

560

561

562

563

564

565

566

567

568

569

570

571

572

573

574

575

576

577

578

579

580

581

582

583

584

585

586

587

588

589

590

591

592

593

594

595

596

597

598

599

600

behavioral control toward more environmentally friendly behaviors.

\section{Inserted Appendix A1 here}

\section{Acknowledgements}

This research was funded by the Ministry of Science and Technology (grant number MOST 1052511-S-003-021-MY3); and subsidized by the National Taiwan Normal University (NTNU), Taiwan, ROC. We would like to thank the principals and teachers in the participating schools, as well as the children and their parents who have contributed to the successful completion of the survey. We are also very grateful to the anonymous reviewers for their constructive feedback that have contributed to the improvement of the manuscript.

\section{References}

Abrahamse W, Steg L, Gifford R, and Vlek C. 2009. Factors influencing car use for commuting and the intention to reduce it: a question of self-interest or morality? Transportation Research Part F: Traffic Psychology and Behaviour 12:317-324.

Ahn J-M, Koo D-M, and Chang H-S. 2012. Different impacts of normative influences on proenvironmental purchasing behavior explained by differences in individual characteristics. Journal of Global Scholars of Marketing Science 22:163-182.

Ajzen I, and Driver BL. 1991. Prediction of leisure participation from behavioral, normative, and control beliefs: An application of the theory of planned behavior. Leisure Sciences 13:185-204. 10.1080/01490409109513137

Ajzen I. 1985. From intentions to actions: a theory of planned behavior. In: Kuhl J, and Beckmann J, eds. Action Control: From Cognition to Behavior. Berlin, Heidelberg: Springer Berlin Heidelberg, 11-39.

Ali MM, Dwyer DS, Vanner EA, and Lopez A. 2010. Adolescent propensity to engage in health risky behaviors: The role of individual resilience. International Journal of Environmental Research and Public Health 7:2161-2176.

Aljomaa SS, AI.Qudah MF, Albursan IS, Bakhiet SF, and Abduljabbar AS. 2016. Smartphone addiction among university students in the light of some variables. Computers in Human Behavior 61:155-164. https://doi.org/10.1016/j.chb.2016.03.041

Bamberg S, and Möser G. 2007. Twenty years after Hines, Hungerford, and Tomera: A new meta-analysis of psycho-social determinants of pro-environmental behaviour. Journal of Environmental Psychology 27:14-25. https://doi.org/10.1016/j.jenvp.2006.12.002

Bandura A. 2006. Toward a psychology of human agency. Perspectives on Psychological Science 1:164-180. 10.1111/j.1745-6916.2006.00011.x

Bertoldo R, and Castro P. 2016. The outer influence inside us: Exploring the relation between social and personal norms. Resources, Conservation and Recycling 112:45-53. https://doi.org/10.1016/j.resconrec.2016.03.020

Bortoleto AP, Kurisu KH, and Hanaki K. 2012. Model development for household waste prevention behaviour. Waste Management 32:2195-2207. https://doi.org/10.1016/j.wasman.2012.05.037

Chan L, and Bishop B. 2013. A moral basis for recycling: Extending the theory of planned behaviour. Journal of Environmental Psychology 36:96-102.

Chang F-C, Chiu C-H, Chen P-H, Chiang J-T, Miao N-F, Chuang H-Y and Liu S. 2019. Children's use of mobile devices, smartphone addiction and parental mediation in

Peer] reviewing PDF | (2020:10:54057:2:0:NEW 21 May 2021) 
601

602

603

604

605

606

607

608

609

610

611

612

613

614

615

616

617

618

619

620

621

622

623

624

625

626

627

628

629

630

631

632

633

634

635

636

637

638

639

640

641

642

643

644

645

646

647

648

649

Taiwan. Computers in Human Behavior 93:25-32.

https://doi.org/10.1016/j.chb.2018.11.048

Chang YT, and Chu YH. 2007. Traditionalism, political learning and conceptions of democracy in East Asia. A Comparative Survey of Democracy, Governance, and Development, Working Paper Series, 39.

Chiang JT, Chang FC, Lee KW, Hsu SY. 2019. Transitions in smartphone addiction proneness among children: The effect of gender and use patterns. PloS One 14, 5, e0217235. doi: 10.1371/journal.pone.0217235

Chiu S-I. 2014. The relationship between life stress and smartphone addiction on Taiwanese university student: A mediation model of learning self-efficacy and social self-efficacy. Computers in Human Behavior 34:49-57. https://doi.org/10.1016/j.chb.2014.01.024

Choi H-S, Lee H-K, and Ha J-C. 2012. The influence of smartphone addiction on mental health, campus life and personal relations-Focusing on $\mathrm{K}$ university students. Journal of the Korean Data and Information Science Society 23:1005-1015.

Culiberg B, and Elgaaied-Gambier L. 2016. Going green to fit in-understanding the impact of social norms on pro-environmental behaviour, a cross-cultural approach. International Journal of Consumer Studies 40:179-185.

De Leeuw A, and Valois P. 2014. Understanding primary-school students' beliefs regarding the adoption of pro-environmental behaviors. International Journal of Education, Economics, and Management Engeneering 8:1391-1395.

De Leeuw A, Valois P, Ajzen I, and Schmidt P. 2015. Using the theory of planned behavior to identify key beliefs underlying pro-environmental behavior in high-school students: Implications for educational interventions. Journal of Environmental Psychology 42:128138.

Dennison L, Morrison L, Conway G, and Yardley L. 2013. Opportunities and challenges for smartphone applications in supporting health behavior change: qualitative study. Journal of Medical Internet Research 15:e86.

Duron-Ramos MF, Collado S, García-Vázquez FI, and Bello-Echeverria M. 2020. The role of urban/rural environments on Mexican children's connection to nature and proenvironmental behavior. Frontiers in Psychology 11:514.

Erdogan M, and Ok A. 2011. An Assessment of Turkish Young Pupils' Environmental Literacy: A nationwide survey. International Journal of Science Education 33:2375-2406. 10.1080/09500693.2010.550653

Esfandiar K, Pearce J, and Dowling R. 2019. Personal norms and pro-environmental binning behaviour of visitors in national parks: the development of a conceptual framework. Tourism Recreation Research 44:163-177.

Fang, W-T, Ng E, and Chang M-C. 2017. Physical outdoor activity versus indoor activity: Their Influence on environmental behaviors. International Journal of Environmental Research and Public Health 14:797.

Fang, W-T, Ng E, and Zhan Y-S. 2018. Determinants of pro-environmental behavior among young and older farmers in Taiwan. Sustainability 10:2186.

Farrow K, Grolleau G, and Ibanez L. 2017. Social norms and pro-environmental behavior: A review of the evidence. Ecological Economics 140:1-13.

Ferdinando F, Giuseppe C, Paola P, and Mirilia B. 2011. Distinguishing the sources of normative influence on proenvironmental behaviors: The role of local norms in household waste recycling. Group Processes \& Intergroup Relations 14:623-635. $10.1177 / 1368430211408149$

Fletcher R. 2017. Gaming conservation: Nature 2.0 confronts nature-deficit disorder. Geoforum 79:153-162. https://doi.org/10.1016/j.geoforum.2016.02.009 
650

651

652

653

654

655

656

657

658

659

660

661

662

663

664

665

666

667

668

669

670

671

672

673

674

675

676

677

678

679

680

681

682

683

684

685

686

687

688

689

690

691

692

693

694

695

696

697

698

Foundation TCWL. 2019a. Children's obsession over social media: Four hidden crises. Available at https://www.children.org.tw/news/advocacy_detail/2228?fbclid=IwAR1RCOcWXPH8ky8 MqGnwVT8WpGZw4ofeWt-LDre1Tj8T5vY4GOBWPS1hf-M (accessed 20 Oct 2020.

Foundation TCWL. 2019b. Research report on children's usage of social media software 2019. Available at https://www.children.org.tw/research/detail/67/1525 (accessed 20 oct 2020.

Gao Y, Li A, Zhu T, Liu X, and Liu X. 2016. How smartphone usage correlates with social anxiety and loneliness. PeerJ 4:e2197. 10.7717/peerj.2197

Gholamrezai S, Aliabadi V, and Ataei P. 2021. Understanding the pro-environmental behavior among green poultry farmers: Application of behavioral theories. Environment, Development and Sustainability 1-19.

Glanz K, Rimer BK, and Viswanath K. 2015. Health Behavior: Theory, Research, and Practice: John Wiley \& Sons.

Gökçearslan Ş, Mumcu FK, Haşlaman T, and Çevik YD. 2016. Modelling smartphone addiction: The role of smartphone usage, self-regulation, general self-efficacy and cyberloafing in university students. Computers in Human Behavior 63:639-649.

Hair Jr JF, Hult GTM, Ringle C, and Sarstedt M. 2016. A Primer on Partial Least Squares Structural Equation Modeling (PLS-SEM): Sage publications.

Hair Jr JF, Sarstedt M, Hopkins L, and Kuppelwieser VG. 2014. Partial Least Squares Structural Equation Modeling (PLS-SEM). European business review.

Han H. 2015. Travelers' pro-environmental behavior in a green lodging context: Converging value-belief-norm theory and the theory of planned behavior. Tourism Management 47:164-177. https://doi.org/10.1016/j.tourman.2014.09.014

Han Y, and Hansen H. 2012. Determinants of Sustainable Food Consumption: A meta-analysis using a traditional and a structura equation modelling approach. International Journal of Psychological Studies 4:22.

Haug S, Castro RP, Kwon M, Filler A, Kowatsch T, and Schaub MP. 2015. Smartphone use and smartphone addiction among young people in Switzerland. Journal of Behavioral Addictions 4:299-307.

Heider F. 2013. The Psychology of Interpersonal Relations: Psychology Press.

Henseler J. 2017. Partial least squares path modeling. Advanced Methods for Modeling Markets: Springer, 361-381.

Hsinchu Science Park. 2016. 2016 Annual Report. Hsinchu City, Taiwan.

Jeong S-H, Kim H, Yum J-Y, and Hwang Y. 2016. What type of content are smartphone users addicted to?: SNS vs. games. Computers in Human Behavior 54:10-17.

Kadir D, Mehmet A, and Abdullah A. 2015. Relationship of smartphone use severity with sleep quality, depression, and anxiety in university students. Journal of Behavioral Addictions JBA 4:85-92. 10.1556/2006.4.2015.010

Kaiser FG, Hübner G, and Bogner FX. 2005. Contrasting the Theory of Planned Behavior With the Value-Belief-Norm Model in explaining conservation behavior. Journal of Applied Social Psychology 35:2150-2170. https://doi.org/10.1111/j.1559-1816.2005.tb02213.x

Kang S, and Jung J. 2014. Mobile communication for human needs: A comparison of smartphone use between the US and Korea. Computers in Human Behavior 35:376387. https://doi.org/10.1016/j.chb.2014.03.024

Kassin S, and Fein S. 2010. Social Psychology. Eight Edition. Wadsworth: Cengage Learning.

Kesebir S, and Kesebir P. 2017. A growing disconnection from nature is evident in cultural products. Perspectives on Psychological Science 12:258-269. 10.1177/1745691616662473

Peer] reviewing PDF | (2020:10:54057:2:0:NEW 21 May 2021) 
699

700

701

702

703

704

705

706

707

708

709

710

711

712

713

714

715

716

717

718

719

720

721

722

723

724

725

726

727

728

729

730

731

732

733

734

735

736

737

738

739

740

741

742

743

744

745

746

747

Kollmuss A, and Agyeman J. 2002. Mind the Gap: Why do people act environmentally and what are the barriers to pro-environmental behavior? Environmental Education Research 8:239-260. 10.1080/13504620220145401

Lapinski MK, and Rimal RN. 2005. An explication of social norms. Communication Theory 15:127-147.

Lee K. 2011. Understanding Hong Kong adolescents' environmental intention: the roles of media exposure, subjective norm, and perceived behavioral control. Applied Environmental Education \& Communication 10:116-125.

Lee S-J, Choi MJ, Rho MJ, Kim D-J, and Choi IY. 2018. Factors affecting user acceptance in overuse of smartphones in mobile health services: An empirical study testing a modified integrated model in South Korea. Frontiers in Psychiatry 9:658.

Lee Y-K, Chang C-T, Lin Y, and Cheng Z-H. 2014. The dark side of smartphone usage: Psychological traits, compulsive behavior and technostress. Computers in Human Behavior 31:373-383. https://doi.org/10.1016/j.chb.2013.10.047

Lemola S, Perkinson-Gloor N, Brand S, Dewald-Kaufmann JF, and Grob A. 2015. Adolescents' electronic media use at night, sleep disturbance, and depressive symptoms in the smartphone age. Journal of Youth and Adolescence 44:405-418.

Leung YW, and Rosenthal S. 2019. Explicating perceived sustainability-related climate: a situational motivator of pro-environmental behavior. Sustainability 11:231.

Liu S, Chiang Y-T, Tseng C-C, Ng E, Yeh G-L, and Fang W-T. 2018. The Theory of Planned Behavior to predict protective behavioral intentions against PM2.5 in parents of young children from urban and rural Beijing, China. International Journal of Environmental Research and Public Health 15. 10.3390/ijerph15102215

Miles R, Zaheer H, and Mark DG. 2018. Problematic smartphone use, nature connectedness, and anxiety. Journal of Behavioral Addictions 7:109-116. 10.1556/2006.7.2018.10

Onu D, Oats L, and Kirchler E. 2019. The dynamics of internalised and extrinsic motivation in the ethical decision-making of small business owners. Applied Psychology 68:177-201.

Paluck EL, Ball L, Poynton C, and Sieloff S. 2010. Social Norms Marketing Aimed at Gender Based Violence: A Literature Review and Critical Assessment. New York: International Rescue Committee.

Park N, Kim Y-C, Shon HY, and Shim H. 2013. Factors influencing smartphone use and dependency in South Korea. Computers in Human Behavior 29:1763-1770. https://doi.org/10.1016/j.chb.2013.02.008

Pett MA, Lackey NR, and Sullivan JJ. 2003. Making Sense of Factor Analysis: The Use of Factor Analysis for Instrument Development in Health Care Research: Sage.

Quinn C, and Burbach ME. 2008. Personal characteristics preceding pro-environmental behaviors that improve surface water quality. Great Plains Research 18: 103-114.

Richardson M, Hussain Z, and Griffiths MD. 2018. Problematic smartphone use, nature connectedness, and anxiety. Journal of Behavioral Addictions 7:109-116.

Ru X, Wang S, and Yan S. 2018. Exploring the effects of normative factors and perceived behavioral control on individual's energy-saving intention: An empirical study in eastern China. Resources, Conservation and Recycling 134:91-99.

Samaha M, and Hawi NS. 2016. Relationships among smartphone addiction, stress, academic performance, and satisfaction with life. Computers in Human Behavior 57:321-325. https://doi.org/10.1016/j.chb.2015.12.045

Schwartz SH. 1977. Normative influences on altruism. In: Leonard B, ed. Advances in Experimental Social Psychology: Academic Press, 221-279.

Schwarzer R, and Warner LM. 2013. Perceived self-efficacy and its relationship to resilience. In Resilience in children, adolescents, and adults (pp. 139-150), Springer, New York, NY.

Peer) reviewing PDF | (2020:10:54057:2:0:NEW 21 May 2021) 
748

749

750

751

752

753

754

755

756

757

758

759

760

761

762

763

764

765

766

767

768

769

770

771

772

773

774

775

776

777

778

779

780

781

782

783

784

785

786

787

788

789

790

791

792

793

794

795

796

797

Song J, and Li W. 2019. Linkage between the environment and individual resilience to urban flooding: a case study of Shenzhen, China. International Journal of Environmental Research and Public Health 16:2559.

Statista. 2020. Number of Smartphone Users Worldwide from 2016 to 2021. Available at https://www.statista.com/statistics/330695/number-of-smartphone-users-worldwide/ (accessed 20 Oct 2020).

Stern PC, Dietz T, Abel TD, Guagnano GA, and Kalof L. 1999. A value-belief-norm theory of support for social movements: The case of environmentalism. Human Ecology Review 6:81-97.

Susanto A, Chang Y, and Ha Y. 2016. Determinants of continuance intention to use the smartphone banking services: An extension to the expectation-confirmation model. Industrial Management \& Data Systems 116:508-525. 10.1108/IMDS-05-2015-0195

Tchetchik A, Kaplan S, and Blass V. 2021. Recycling and consumption reduction following the COVID-19 lockdown: The effect of threat and coping appraisal, past behavior and information. Resources, Conservation and Recycling 167:105370.

Thøgersen J. 2006. Norms for environmentally responsible behaviour: An extended taxonomy. Journal of Environmental Psychology 26:247-261. https://doi.org/10.1016/j.jenvp.2006.09.004

Tian M, Tao R, Zheng Y, Zhang H, Yang G, Li Q, and Liu X. 2018. Internet gaming disorder in adolescents is linked to delay discounting but not probability discounting. Computers in Human Behavior 80:59-66. https://doi.org/10.1016/j.chb.2017.10.018

Turaga RMR, Howarth RB, and Borsuk ME 2010. Pro-environmental behavior. Annals of the New York Academy of Sciences 1185:211-224.

Vu HT, Tran D, Goto D, and Kawata K. 2020. Does experience sharing affect farmers' proenvironmental behavior? A randomized controlled trial in Vietnam. World Development 136:105062.

Wall R, Devine-Wright P, and Mill GA. 2008. Interactions between perceived behavioral control and personal-normative motives: Qualitative and quantitative evidence from a study of commuting-mode choice. Journal of Mixed Methods Research 2:63-86.

Wang C, Zhang J, Yu P, and Hu H. 2018. The theory of planned behavior as a model for understanding tourists' responsible environmental behaviors: The moderating role of environmental interpretations. Journal of Cleaner Production 194:425-434.

Wang J-L, Wang H-Z, Gaskin J, and Wang L-H. 2015. The role of stress and motivation in problematic smartphone use among college students. Computers in Human Behavior 53:181-188. https://doi.org/10.1016/j.chb.2015.07.005

Wated G, and Sanchez, JI 2005. The effects of attitudes, subjective norms, attributions, and individualism-collectivism on managers' responses to bribery in organizations: Evidence from a developing nation. Journal of Business Ethics 61:111-127.

Weiner B. 2001. Intrapersonal and interpersonal theories of motivation from an attribution perspective. In Student Motivation. Boston, Springer,17-30.

Westwood RI, and Chan A. 1995. The transferability of leadership training in the East Asian context. Asia Pacific Business Review 2:68-92.

Xu X, Wang L, Wang L, and Xue K. 2020. Effects of online service failure on customers' intentions to complain online. Social Behavior and Personality: An International Journal 48:1-16.

Yoon J, and Lee S. 2016. What makes employees zealous supporters of their firm's CSR initiative? the role of employees' perceptions of their firm's CSR authenticity. In Advances in Group Processes. Emerald Group Publishing Limited.

Zhang D, Huang G, Yin X, and Gong Q. 2015. Residents' waste separation behaviors at the source: Using SEM with the theory of planned behavior in Guangzhou, China.

Peer) reviewing PDF | (2020:10:54057:2:0:NEW 21 May 2021) 
798 International Journal of Environmental Research and Public Health 12:9475-9491. DOI: $799 \quad$ 10.3390/ijerph120809475

800 Zimmerman BJ. 2000. Attaining self-regulation: A social cognitive perspective. Handbook of 801 self-regulation. San Diego: Academic Press, 13-39. http://dx.doi.org/10.1016/B978-

$802 \quad$ 012109890-2/50031-7 Elsevier

803 
Figure 1

Proposed research framework

Social norms is a key component of external attributions that goes beyond attitudes that shape people's behaviors, and can be further classified as (1) subjective norms, and (2) descriptive norms.

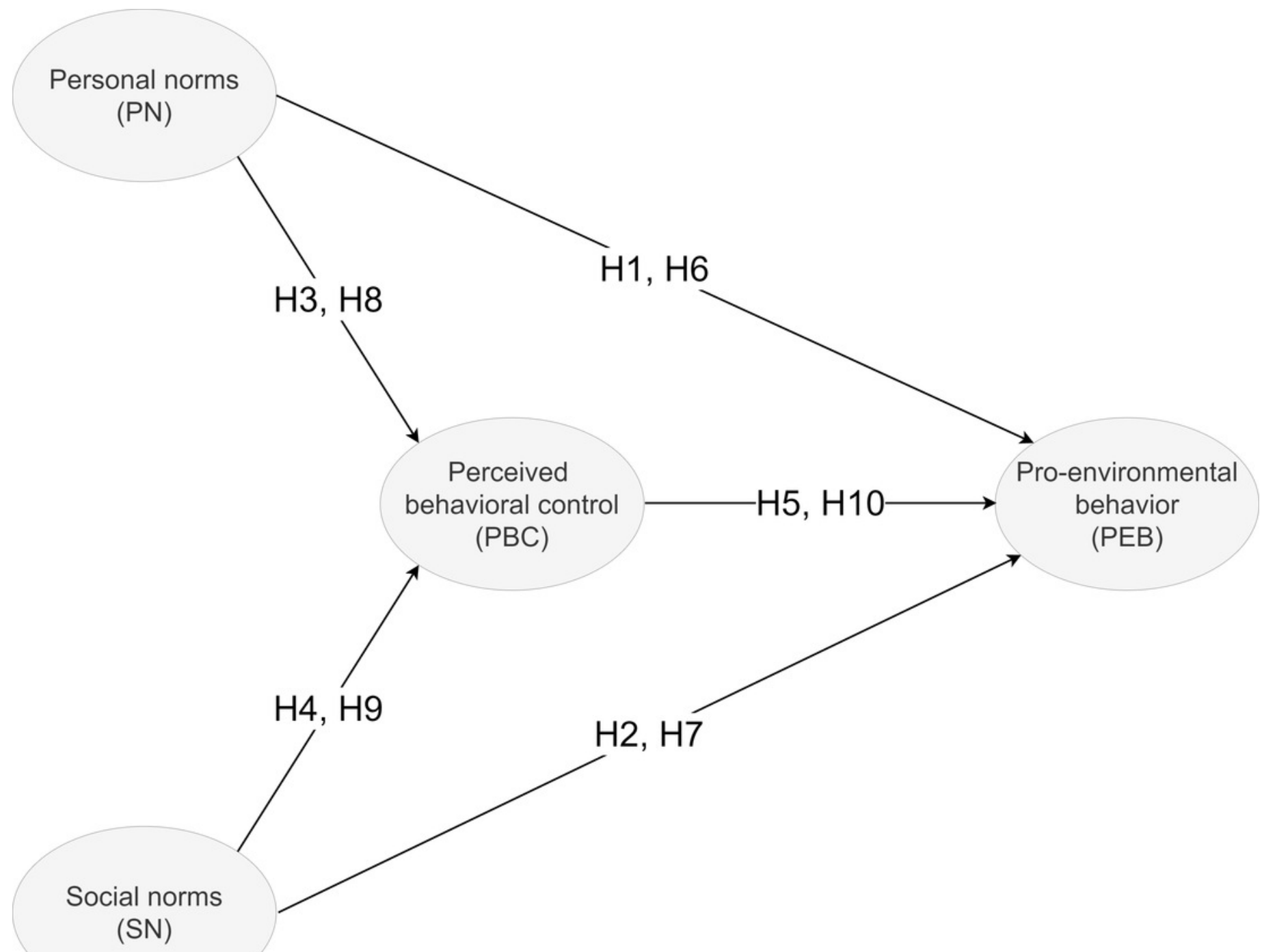


Figure 2

Path diagram on personal norms (PN), social norms (SN), perceived behavioral control $(\mathrm{PBC})$, and pro-environmental behavior (PEB) of excessive smartphone usage children

Figure 2 displayed the path analysis about the relationship between personal norms, social norms, perceived behavioral control, and pro-environmental behavior of excessive smartphone usage children.

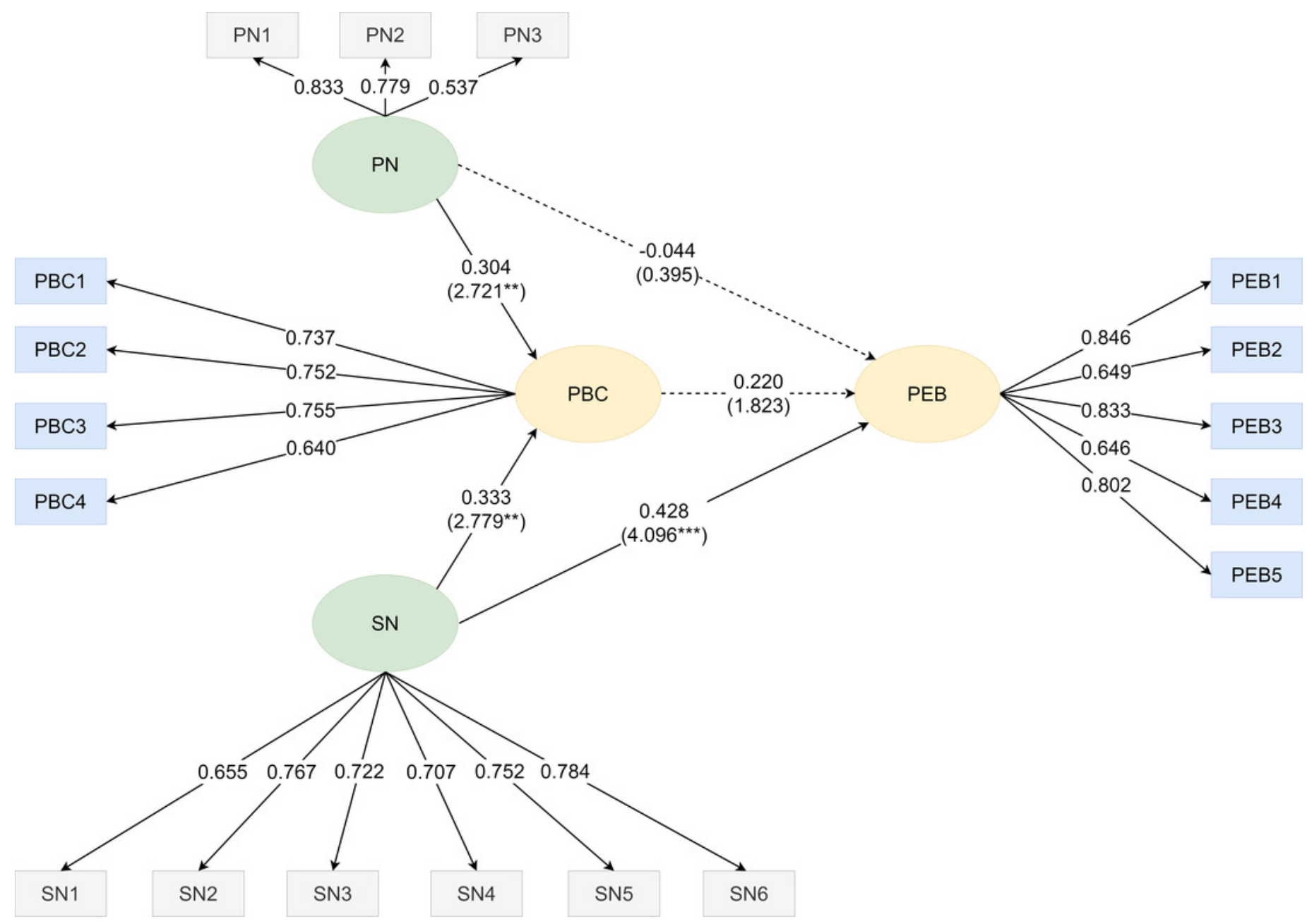


Figure 3

Path diagram on personal norms (PN), social norms (SN), perceived behavioral control $(\mathrm{PBC})$, and pro-environmental behavior (PEB) of moderate smartphone usage children

Figure 3 displayed the relationship between personal norms, social norms, perceived behavioral control, and pro-environmental behavior of moderate smartphone usage children.

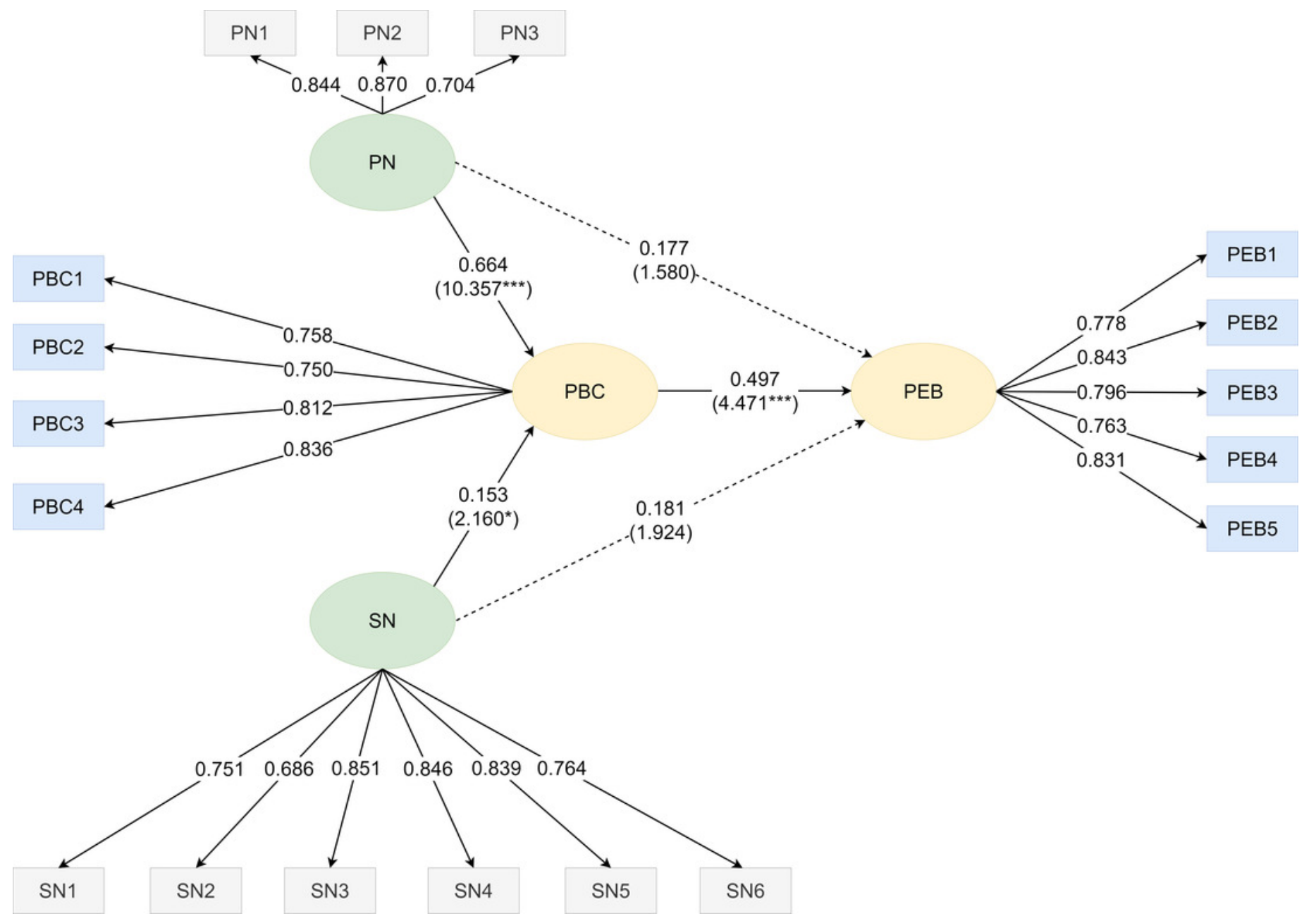




\section{Table $\mathbf{1}$ (on next page)}

Descriptive statistics related to the demographic questions for personal norms, social norms, perceived behavioral control, and pro-environmental behavior

Table 1 presents a brief summary of the demographic findings and their association with personal norms, social norms, perceived behavioral control, and pro-environmental behavior. 
1 Table 1. Descriptive statistics related to the demographic questions for personal norms, social norms, perceived behavioral control, 2 and pro-environmental behavior

3

\begin{tabular}{|c|c|c|c|c|c|c|c|c|c|c|c|c|c|c|c|c|c|c|}
\hline \multirow{2}{*}{ Variables } & \multirow{2}{*}{$\begin{array}{l}\text { Freque } \\
\text { ncy }\end{array}$} & \multirow{2}{*}{$\begin{array}{l}\text { Percen } \\
\text { t (\%) }\end{array}$} & \multicolumn{4}{|c|}{ Personal norms } & \multicolumn{4}{|c|}{ Social norms } & \multicolumn{4}{|c|}{ Perceived behavioral control } & \multicolumn{4}{|c|}{ Pro-environmental behavior } \\
\hline & & & Mean & SD & $t$ & $p$ & Mean & SD & $t$ & $p$ & Mean & SD & $t$ & $p$ & Mean & SD & $t$ & $p$ \\
\hline \multicolumn{19}{|l|}{ Gender } \\
\hline Female & 115 & 51.1 & 3.76 & 0.791 & & & 3.60 & 0.78 & & & 3.73 & 0.78 & & & 3.43 & 0.96 & & \\
\hline Male & 110 & 48.9 & 3.59 & 0.777 & 1.000 & ו & 3.48 & 0.78 & 1.101 & 0.247 & 3.50 & 0.84 & 2.120 & 0.035 & 3.21 & 0.91 & 1.100 & 0.070 \\
\hline \multicolumn{19}{|l|}{ Grade level } \\
\hline Grade 6 & 118 & 52.4 & 3.58 & 0.76 & & & 3.51 & 0.75 & & & 3.49 & 0.81 & & & 3.25 & 0.88 & & \\
\hline Grade 5 & 107 & 47.6 & 3.80 & 0.81 & -2.095 & 0.037 & 3.58 & 0.82 & -0.655 & 0.513 & 3.76 & 0.80 & -2.498 & 0.013 & & 1.00 & -1.101 & 0.272 \\
\hline \multicolumn{19}{|l|}{$\begin{array}{l}\text { Smartphone } \\
\text { usage }\end{array}$} \\
\hline Excessive & 96 & 42.7 & 3.41 & 0.71 & & & 3.43 & 0.68 & & & 3.40 & 0.80 & & & 3.07 & 0.90 & & \\
\hline Moderate & 129 & 57.3 & 3.89 & 0.78 & -4.095 & 0.000 & 3.75 & 0.74 & -0.203 & 0.002 & 3.78 & 0.80 & -3.403 & 0.001 & 3.50 & 0.93 & $-5.5<0$ & 0.001 \\
\hline
\end{tabular}




\section{Table 2 (on next page)}

Descriptive statistics for perceived behavioral control related items.

As shown in Table 2, the mean score for the overall perceived behavioral control was 3.62. 
1 Table 2. Descriptive statistics for perceived behavioral control related items

\begin{tabular}{|l|l|l|}
\hline Perceived behavioral control & Mean & SD \\
\hline PBC1. I take the initiative to go outdoors. & 3.38 & 1.16 \\
\hline $\begin{array}{l}\text { PBC2. I have involvement in and disseminate information beneficial to } \\
\text { the environment. }\end{array}$ & 3.37 & 1.05 \\
\hline PBC3. I can save water resources. & 3.92 & 1.07 \\
\hline PBC4. I can observe environmental cleanliness. & 3.80 & 0.96 \\
\hline Overall perceived behavioral control & 3.62 & 0.82 \\
\hline
\end{tabular}

2

3 


\section{Table 3(on next page)}

Descriptive statistics for personal norms related items.

There was a consistent reliable measurement for the personal norms related items with the Cronbach's $\alpha$ value of 0.766 . 
1 Table 3. Descriptive statistics for personal norms related items

\begin{tabular}{|l|l|l|}
\hline Personal norms & Mean & SD \\
\hline PN1. For self-discipline, I carry my own cutlery when I go out. & 3.70 & 1.08 \\
\hline PN2. For self-discipline, I carry my own water cup when I go out. & 3.79 & 1.06 \\
\hline $\begin{array}{l}\text { PN3. I must not arbitrarily abandon pets or plant garden plants in the } \\
\text { wild. }\end{array}$ & 3.45 & 1.08 \\
\hline Overall personal norms & 3.68 & 0.79 \\
\hline
\end{tabular}

2

3 


\section{Table 4 (on next page)}

Descriptive statistics for social norms related items.

Results indicated that the mean score for the overall social norms was 3.61. 
1 Table 4. Descriptive statistics for social norms related items

\begin{tabular}{|l|l|l|}
\hline Social norms & Mean & SD \\
\hline $\begin{array}{l}\text { SN1. People I know want me to carry a water cup and cutlery when I go } \\
\text { out. }\end{array}$ & 3.63 & 1.05 \\
\hline $\begin{array}{l}\text { SN2. People I know want me to go outdoors instead of staying indoors } \\
\text { with air conditioning. }\end{array}$ & 3.68 & 0.13 \\
\hline SN3. People I know carry their own cutlery when they go out. & 3.59 & 1.06 \\
\hline SN4. People I know are aware of how to save water. & 3.77 & 1.01 \\
\hline SN5. People I know do not litter arbitrarily. & 3.78 & 1.01 \\
\hline SN6. People I know go outdoors instead of staying indoors with air & 3.22 & 1.22 \\
\hline conditioning. & & 3.61 \\
\hline Overall social norms & 0.79 \\
\hline
\end{tabular}

2

3 


\section{Table 5 (on next page)}

Descriptive statistics for pro-environmental behavior related items.

Results of the pro-environmental behavior related items are outlined in Table 5 below. The internal consistency reliability for the pro-environmental behaviors related items was measured, with the Cronbach's $\alpha$ value of 0.846 . 
1 Table 5. Descriptive statistics for pro-environmental behavior related items

\begin{tabular}{|l|l|l|}
\hline Pro-environmental behavior & Mean & SD \\
\hline PEB1. I persuade others to sort waste. & 3.34 & 1.211 \\
\hline PEB2. I go into nature in my free time instead of using smartphone. & 3.62 & 1.174 \\
\hline PEB3. I participate in environmental activities conducted outdoors. & 2.97 & 1.185 \\
\hline $\begin{array}{l}\text { PEB4. I participate in conducting surveys on animal and plant-related } \\
\text { activities in the vicinity of the community. }\end{array}$ & 3.52 & 1.203 \\
\hline PEB5. I visit the park and volunteer. & & 1.200 \\
\hline Overall pro-environmental behavior & 3.14 & 0.940 \\
\hline
\end{tabular}

2

3 


\section{Table 6(on next page)}

Pearson's correlation matrix (Mean).

The correlation coefficient of the remaining relationships indicated a moderate correlation; social norms and perceived behavioral control $(r=0.520, p<0.01)$; perceived behavioral control and pro-environmental behavior $(r=0.598, p<0.01)$; personal norms and proenvironmental behavior $(r=0.536, p<0.01)$; social norms and pro-environmental behavior $(r=0.522, p<0.01)$. 
1 Table 6. Pearson's correlation matrix (Mean)

\begin{tabular}{|c|c|c|c|c|}
\hline & $\begin{array}{l}\text { Personal } \\
\text { norms }\end{array}$ & $\begin{array}{l}\text { Social } \\
\text { norms }\end{array}$ & $\begin{array}{l}\text { Perceived } \\
\text { behavioral } \\
\text { control }\end{array}$ & $\begin{array}{l}\text { Pro- } \\
\text { environmental } \\
\text { behavior }\end{array}$ \\
\hline Personal norms & 1.000 & & & \\
\hline Social norms & 0.559 & 1.000 & & \\
\hline $\begin{array}{l}\text { Perceived behavioral } \\
\text { control }\end{array}$ & 0.723 & 0.520 & 1.000 & \\
\hline $\begin{array}{l}\text { Pro-environmental } \\
\text { behavior }\end{array}$ & 0.536 & 0.522 & 0.598 & 1.000 \\
\hline
\end{tabular}

2 All correlations are significant, $p<0.01$ (two-tailed test).

3 


\section{Table 7 (on next page)}

Partial least square regression analysis of personal norms, social norms, and perceived behavioral control that predict pro-environmental behavior of excessive smartphone usage children $(n=96)$.

Results of the partial least squares regression analysis indicated different paths influencing pro-environmental behavior for both excessive smartphone usage, and moderate smartphone usage children. In the excessive smartphone usage group. 
1 Table 7. Partial least square regression analysis of personal norms, social norms, and perceived

2 behavioral control that predict pro-environmental behavior of excessive smartphone usage

3 children $(n=96)$

\begin{tabular}{|l|l|l|l|l|}
\hline & AVE & CR & $\mathbf{R}^{2}$ & $\begin{array}{l}\text { Cronbach's } \\
\boldsymbol{\alpha}\end{array}$ \\
\hline Personal norms & 0.5297 & 0.7660 & & 0.5604 \\
\hline Social norms & 0.5363 & 0.8736 & & 0.8280 \\
\hline Perceived behavioral control & 0.5219 & 0.8130 & 0.2865 & 0.6976 \\
\hline Pro-environmental behavior & 0.5782 & 0.8711 & 0.2964 & 0.8173 \\
\hline
\end{tabular}

4

5 


\section{Table 8(on next page)}

Partial least square regression analysis of personal norms, social norms, and perceived behavioral control that predict pro-environmental behavior of moderate smartphone usage children $(n=129)$.

All of the convergent validity, i.e. average variance extracted (AVE) values had exceeded 0.50 , and similarly the composite reliability $(C R)$ values were above 0.70 . 
1 Table 8. Partial least square regression analysis of personal norms, social norms, and perceived

2 behavioral control that predict pro-environmental behavior of moderate smartphone usage

3 children $(n=129)$

\begin{tabular}{|l|l|l|l|l|}
\hline & AVE & CR & $\mathbf{R}^{\mathbf{2}}$ & Cronbach's $\boldsymbol{\alpha}$ \\
\hline Personal norms & 0.6549 & 0.8496 & & 0.7309 \\
\hline Social norms & 0.6270 & 0.9093 & & 0.8794 \\
\hline Perceived behavioral control & 0.6240 & 0.8688 & 0.5697 & 0.7989 \\
\hline Pro-environmental behavior & 0.6441 & 0.9004 & 0.5684 & 0.8618 \\
\hline
\end{tabular}

4

5 
Table 9 (on next page)

\section{Appendix A1}

Appendix A1: Survey Questionnaire 20170810Ver2 


\section{Manuscript to be reviewed}

\section{Appendix A1: Survey QuestionnaireSurvey Questionnaire}

20170810Ver2

\section{A. Questionnaire introduction and informed consent for study participants}

To whom it may concern:

This is a survey questionnaire on environmental protection behaviors and learning model subsidized by the Ministry of Science and Technology, Taiwan. The main aim of this questionnaire is to gain a better understanding on the model of environmental protection behaviors. The subjects of the survey are students in grades five and six, age between 11 to 12. Participants and their parents are to sign the written informed consent prior to completing the questionnaire. Please note that each questionnaire can take approximately 15 minutes to complete. Thank you for taking the time to complete it.

This questionnaire has been designed to be completed anonymously and will not identify any individual participant. The research team will take all reasonable steps to maintain your privacy and the confidentiality of the data collected. This research results will be published in academic journals with findings reported as a summary where no individuals will be identified. There are no commercial benefits derived from this study.

Please do not feel obliged to participate in this study, however, once you have submit the written informed consent form, you are deemed to agree to participate. Since this questionnaire is not pre-coded for any identification purpose, therefore the research team will not be able to delete the questionnaire and its contents once it has been filled out and submitted.

If you wish to inquire about the content of this questionnaire, or are interested in knowing the results of the research, you are welcome to request a summary of the research results by contacting (Project PI: Wei-Ta Fang, Tel:02-77496558, email:wtfang@ ntnu.edu.tw). Graduate Institute of Environmental Education, National Taiwan Normal University

Professor and Director Wei-Ta Fang Graduate Institute of Environmental Education, NTNU 


\section{B. Basic information}

1. Name of school: Elementary School.

2. Grade level: $\square$ Grade $5 \square$ Grade 6

3. Gender: $\square$ Male $\square$ Female

4. Parent's educational level:

(1) Father:

$\square$ Below middle school (including middle school) $\square$ High school $\square$ Bachelor's degree

$\square$ Master's degree $\square \mathrm{PhD}$

(2) Mother:

$\square$ Below middle school (including middle school) $\square$ High school $\square$ Bachelor's degree $\square$ Master's degree $\square \mathrm{PhD}$

5. Parent's occupation

(1) Father:

$\square$ Public servant $\square$ School staff $\square$ Electronics and Information Industry

$\square$ Business and finance $\square$ Law, accounting, architect $\square$ Service industry

$\square$ Transportation $\square$ Self-operated shop owner (retail, catering )

$\square$ Agriculture, forestry, fishery, and animal husbandry $\square$ Unpaid household management $\square$ University professor $\square$ Medical care $\square$ Others:

(2) Mother:

$\square$ Government agency $\square$ School staff $\square$ Electronics and Information Industry

$\square$ Business and finance $\square$ Law, accounting, architect $\square$ Service industry

$\square$ Transportation $\square$ Self-operated shop owner (retail, catering )

$\square$ Agriculture, forestry, fishery and animal husbandry $\square$ Unpaid household management

$\square$ University professor $\square$ Medical care $\square$ Others:

\section{Mobile phone usage}

How many hours per day do you usually spend on smartphone during a typical day?

$\square$ none $\square$ less than 1 hour $\square$ between 1 to 2 hours $\square$ between 2 to 3 hours

$\square$ between 3 to 4 hours $\square$ between 4 to 5 hours $\square$ more than 5 hours 
D. Social norms, perceived behavioral control, and pro-environmental behavior

\begin{tabular}{|c|c|c|c|c|c|}
\hline $\begin{array}{l}\text { Please fill in the level of agreement to the best of } \\
\text { your understanding on the following statements. }\end{array}$ & $\begin{array}{l}\text { Strongly } \\
\text { disagree } \\
\text { (1) }\end{array}$ & $\begin{array}{l}\text { Disagree } \\
\text { (2) }\end{array}$ & $\begin{array}{c}\text { Neither } \\
\text { agree } \\
\text { nor } \\
\text { disagree } \\
\text { (3) }\end{array}$ & $\begin{array}{l}\text { Agree } \\
(4)\end{array}$ & $\begin{array}{l}\text { Strongly } \\
\text { agree } \\
(5)\end{array}$ \\
\hline I take the initiative to go outdoors. & $\square$ & $\square$ & $\square$ & $\square$ & $\square$ \\
\hline $\begin{array}{l}\text { I have involvement in and disseminate information beneficial to } \\
\text { the environment. }\end{array}$ & $\square$ & $\square$ & $\square$ & $\square$ & $\square$ \\
\hline I can save water resources. & $\square$ & $\square$ & $\square$ & $\square$ & $\square$ \\
\hline I can observe environmental cleanliness. & $\square$ & $\square$ & $\square$ & $\square$ & $\square$ \\
\hline For self-discipline, I carry my own cutlery when I go out. & $\square$ & $\square$ & $\square$ & $\square$ & $\square$ \\
\hline For self-discipline, I carry my own water cup when I go out. & $\square$ & $\square$ & $\square$ & $\square$ & $\square$ \\
\hline $\begin{array}{l}\text { I must not arbitrarily abandon pets or plant garden plants in the } \\
\text { wild. }\end{array}$ & $\square$ & $\square$ & $\square$ & $\square$ & $\square$ \\
\hline $\begin{array}{l}\text { People I know want me to carry a water cup and cutlery when I go } \\
\text { out. }\end{array}$ & $\square$ & $\square$ & $\square$ & $\square$ & $\square$ \\
\hline $\begin{array}{l}\text { People I know want me to go outdoors instead of staying indoors } \\
\text { with air conditioning. }\end{array}$ & $\square$ & $\square$ & $\square$ & $\square$ & $\square$ \\
\hline People I know carry their own cutlery when they go out. & $\square$ & $\square$ & $\square$ & $\square$ & $\square$ \\
\hline People I know are aware of how to save water. & $\square$ & $\square$ & $\square$ & $\square$ & $\square$ \\
\hline People I know do not litter arbitrarily. & $\square$ & $\square$ & $\square$ & $\square$ & $\square$ \\
\hline $\begin{array}{l}\text { People I know go outdoors instead of staying indoors with air } \\
\text { conditioning. }\end{array}$ & $\square$ & $\square$ & $\square$ & $\square$ & $\square$ \\
\hline I persuade others to sort waste. & $\square$ & $\square$ & $\square$ & $\square$ & $\square$ \\
\hline I go into nature in my free time instead of using smartphone. & $\square$ & $\square$ & $\square$ & $\square$ & $\square$ \\
\hline I participate in environmental activities conducted outdoors. & $\square$ & $\square$ & $\square$ & $\square$ & $\square$ \\
\hline $\begin{array}{l}\text { I participate in conducting surveys on animal and plant-related } \\
\text { activities in the vicinity of the community. }\end{array}$ & $\square$ & $\square$ & $\square$ & $\square$ & $\square$ \\
\hline I visit the park and volunteer. & $\square$ & $\square$ & $\square$ & $\square$ & $\square$ \\
\hline
\end{tabular}

